\title{
AS AVALIAÇÕES SOBRE MULHERES E ABORTO NA FOLHA DE SÃO PAULO: UMA ANÁLISE DISCURSIVA CRÍTICA ${ }^{1}$
}

\author{
FOLHA DE SÃO PAULO'S EVALUATIONS ON WOMEN AND \\ ABORTION: A CRITICAL DISCURSIVE ANALYSIS
}

\author{
Maria Aparecida Resende Ottoni (UFU) \\ cidottoni@gmail.com \\ Bianca Mara Guedes de Souza (UFU) \\ biancamgsouza@gmail.com
}

\begin{abstract}
RESUMO: Neste artigo, investigamos as identificações discursivas sobre o aborto e as mulheres que abortaram construídas na prática jornalística. Dentre as várias facetas da temática, discutiremos, neste trabalho, a prática legal ou despenalizada no Brasil. Para isso, selecionamos um texto da Folha de São Paulo e apoiamo-nos na Análise de Discurso Crítica $(A D C)$, especificamente na abordagem Dialético-Relacional (CHOULIARAKI; FAIRCLOUGH, 1999; FAIRCLOUGH, 2001; 2010), no Sistema da Avaliatividade (MARTIN; WHITE, 2005) e na Linguística Sistêmico-Funcional (HALLIDAY; MATTHIESSEN, 2014; FUZER; CABRAL, 2014). Os resultados apontam que o aborto $e$ as mulheres são identificados por meio de avaliações negativas. No caso das mulheres, essas avaliações estão pautadas em fatores emocionais.
\end{abstract}

PALAVRAS-CHAVE: Análise de Discurso Crítica; Sistema da Avaliatividade; aborto; prática jornalística.

ABSTRACT: In this article, we investigate the discursive identifications of abortion and women who had abortions within the journalistic practice. Among the various facets of the subject, in this paper we will discuss the legal or decriminalized practice in Brazil. For this, we selected a text from Folha de São Paulo and we rely on Critical Discourse Analysis (CDA), specifically on the Dialectic-Relational approach (CHOULIARAKI; FAIRCLOUGH, 1999; FAIRCLOUGH, 2001; 2010), on the Appraisal Theory (MARTIN; WHITE, 2005) and Systemic-Functional Linguistics (HALLIDAY; MATTHIESSEN, 2014; FUZER; CABRAL, 2014). The results show that abortion and women are identified through negative evaluations. In the case of women, these assessments are based on emotional factors.

\footnotetext{
${ }^{1}$ Este trabalho foi realizado com o apoio da Coordenação de Aperfeiçoamento de Pessoal de Ensino Superior Brasil - CAPES - Código do financiamento 001.
} 
KEYWORDS: Critical Discourse Analysis; Appraisal Theory; abortion; journalistic practice.

\section{Introdução}

Este artigo é parte de uma pesquisa maior que ainda está em desenvolvimento e que objetiva analisar as representações e as identificações do aborto e das mulheres que abortaram construídas pela prática social jornalística (tradicional e independente) e em relatos de mulheres que realizaram um aborto induzido. Dentre as várias facetas da temática, discutiremos, neste trabalho, a prática legal ou despenalizada. No Brasil, uma mulher ou menina pode buscar a interrupção de uma gravidez quando essa é decorrente de estupro, quando há risco de morte para a gestante ou quando o feto é anencéfalo, de acordo com o artigo 128 do Código Penal (BRASIL, 1940) e com a Arguição de descumprimento de preceito fundamental 54 (ADPF 54) (BRASIL, 2012). Efetivamente, a prática ainda é considerada crime, mas a lei determina esses casos como exceção, nos quais a equipe médica e a gestante não podem ser legalmente punidas. A prática pode ser dimensionada a partir dos dados disponíveis no Sistema de Informações Hospitalares do Sistema Único de Saúde (SIH/SUS), os quais indicam a realização de 9.796 abortos entre os anos de 2015 e 2020 no Brasil.

Rohden (2003, p. 15) explica que as questões de sexo, reprodução e controle de natalidade "[...] estão centradas na dimensão das relações de gênero, que traduzem, sobretudo, relações de poder". Além disso, a autora defende que "o controle sobre a capacidade reprodutiva é um dos nódulos centrais sobre os quais se constroem as prerrogativas em torno das capacidades e das funções sociais de cada gênero". Consideramos que o jornalismo desempenha um papel central na circulação discursiva e que é por meio dele que pessoas de todas as camadas socioeconômicas têm acesso aos temas debatidos em sociedade; entre esses, está o aborto.

Tal tema é recorrente na mídia, e o jornalismo, como um maestro, coordena a sinfonia de vozes e detém o poder de direcionar a opinião de cidadãos, legisladores e políticos acerca do assunto. Sobre o trabalho ideológico da mídia, Fairclough (2001, p. 202) explica que "os jornais tendem a oferecer versões da verdade [...] cada uma das quais se baseia na reivindicação implícita e indefensável de que os eventos podem ser representados transparente e categoricamente e que perspectiva pode ser universalizada". Além disso, o autor argumenta que, ao oferecer imagens e categorias para a realidade, a prática jornalística "posiciona e 
molda os sujeitos sociais e contribui principalmente para o controle e a reprodução social" (FAIRCLOUGH, 2001, p. 202).

É pensando nisso que, neste recorte de nossa pesquisa principal ${ }^{2}$, objetivamos investigar as identificações discursivas das mulheres que abortaram e do tema aborto, construídas em um texto da esfera jornalística publicado no jornal Folha de São Paulo. Partimos do princípio de que "processos e relações de mediação são processos e relações de recontextualização, que envolve especificamente relações entre o campo da mídia e outros campos sociais" (FAIRCLOUGH, 2010, p. 78). Sendo assim, nos textos jornalísticos sobre o aborto, há uma recontextualização de elementos da prática social de abortamento, por meio da qual são construídas diferentes representações e identificações dela e dos atores sociais nela envolvidos. Essas representações e identificações são realizadas nos textos por meio de escolhas lexicogramaticais e imagéticas, por exemplo.

Considerando nosso objetivo, selecionamos a avaliação, entre as categorias propostas por Fairclough (2003), para a análise do significado identificacional. A abordagem dessa categoria é feita à luz dos pressupostos do Sistema da Avaliatividade (SA), que se baseia na Linguística Sistêmico-Funcional (LSF) e no princípio dialógico de Bakhtin. O SA é apresentado em diferentes obras e consubstanciado em Martin e White (2005).

\section{Metodologia}

A pesquisa da qual este artigo é parte configura-se como uma pesquisa qualitativa, descritivo-interpretativista. É qualitativa porque, além de se preocupar com o aprofundamento de uma questão, "preocupa-se [...] com aspectos da realidade que não podem ser quantificados, centrando-se na compreensão e explicação da dinâmica das relações sociais" (SILVEIRA; CÓRDOVA, 1999, p. 31). Também é descritivo-interpretativista, porque não só descreve os textos e os modos como a avaliação é realizada nesses textos, como também se propõe a

\footnotetext{
examinar uma grande variedade de aspectos do processo social, como o tecido social da vida diária, o significado das experiências e o imaginário dos participantes da pesquisa; a forma como se articulam os processos sociais, as instituições, os discursos e as relações sociais, e os significados que produzem. (MAGALHÃES; MARTINS; RESENDE, 2017, p. 25).
}

\footnotetext{
${ }^{2}$ Nessa pesquisa, analisamos material coletado da versão online do jornal Folha de São Paulo, da revista digital Revista AzMina e do blogue Somos Todas Clandestinas.
} 
Em relação aos procedimentos, esta pesquisa é caracterizada como documental (SILVEIRA; CÓRDOVA, 1999), pois é realizada a partir de documentos que, seguindo Gerhardt et al. (2009, p. 69), são tipificados no grupo de fontes primárias (ou de primeira mão). Os documentos desse grupo são “os que não receberam qualquer tratamento analítico", como os textos de jornais.

O corpus utilizado para a análise apresentada neste artigo é composto por uma reportagem publicada no jornal online Folha de São Paulo, em 23 de fevereiro de 2019, e coletada para análise em março de 2020. Selecionamos a Folha de São Paulo, pois entendemos que, enquanto veículo de comunicação, ela pode ser classificada como um jornalismo tradicional e de referência no país. O jornalismo de referência é caracterizado por seu prestígio social, já que é hegemônico e detém poderes simbólicos na organização social; apesar de estar voltado aos resultados econômicos, não renuncia à credibilidade. Para Zamin (2014), o veículo de referência é mediador simbólico e, ao tomar o poder de ordenação dos fatos, impõe-se como referência de uma cultura dominante.

A reportagem analisada foi selecionada por ter sido a primeira reportagem do ano de 2019 publicada na Folha de São Paulo que falava sobre a prática social de aborto no Brasil e tinha entre suas fontes jornalísticas mulheres que abortaram. $\mathrm{Na}$ figura 1 , a seguir, apresentamos a data de publicação, a autoria, o título/manchete, e o subtítulo/linha fina do texto.

\begin{tabular}{|c|c|l|l|}
\hline $\begin{array}{c}\text { Data de } \\
\text { publicação }\end{array}$ & Autoria & Título/Manchete & \multicolumn{1}{|c|}{ Subtítulo/Linha fina } \\
\hline $23 / 02 / 2019$ & Gabriela Sá Pessoa & $\begin{array}{l}\text { Mulheres têm que viajar a São } \\
\text { Paulo por aborto legal }\end{array}$ & $\begin{array}{l}\text { Pacientes têm que ir ao Hospital } \\
\text { Pérola Byington para conseguir } \\
\text { serviço garantido pelo SUS }\end{array}$ \\
\hline
\end{tabular}

Figura $1-\mathrm{O}$ corpus

Fonte: elaborada pelas autoras

Primeiro, fizemos a leitura da reportagem selecionada em busca de uma compreensão global do texto. Em seguida, relemos a matéria buscando as marcas de avaliação por meio das quais as mulheres e o aborto foram identificados no texto. Após esse momento, selecionamos os trechos mais profícuos para análise e organizamo-los nas figuras apresentadas na seção três deste artigo. Por fim, discorremos de forma mais aprofundada sobre as categorias observadas e realizamos algumas indicações de possíveis padrões de escolhas lexicogramaticais presentes em textos da Folha de São Paulo que podem ser discutidos mais profundamente por outros 
trabalhos. Na próxima seção, apresentamos a fundamentação teórica na qual a análise está pautada.

\title{
3 Atitude e Gradação no Sistema da Avaliatividade
}

A abordagem dialético-relacional da ADC, proposta por Fairclough, sempre teve como base a LSF. No entanto, a partir de 2003 com a publicação da obra Analysing discourse: textual analysis for social research, o autor estreita esses laços. Fairclough propõe a divisão de três significados para a análise: o Representacional, o Identificacional e o Acional. Sendo que,

\begin{abstract}
o Representacional corresponde à função 'ideacional' de Halliday; o Acional é mais próximo à função 'interpessoal' dele, embora coloque mais ênfase no texto como uma forma de inter(ação) em eventos sociais, e pode ser visto incorporando Relação (promulgando relações sociais); Halliday não diferencia uma função separada para identificação - a maior parte do que incluo no Identificacional é da função 'interpessoal' dele. Não diferencio uma função 'textual', ao invés disso a incorporo com o Acional. (FAIRCLOUGH, 2003, p. 27, tradução nossa) ${ }^{3}$.
\end{abstract}

Ao tratar do Significado Identificacional ou de Identificação, Fairclough (2003) aponta que a avaliação é uma categoria de análise possível e demostra que o Sistema da Avaliatividade de Martin e White (2005) pode ser utilizado na verificação de identificações. O Sistema da Avaliatividade é "um conjunto de significados interpessoais que se debruça sobre os mecanismos de avaliação veiculados pela linguagem, configurados em um sistema que oferece aos usuários possibilidades de utilizar itens avaliativos em suas interações cotidianas" (VIAN JR; SOUZA; ALMEIDA, 2010, p. 11).

Martin e White (2005, p. 33, tradução nossa) ${ }^{4}$ elucidam que “[...] podemos localizar a avaliação como um sistema interpessoal ao nível da semântica do discurso"; portanto, o Sistema da Avaliatividade interessa-se pelo significado além da oração, pois está ligado à metafunção interpessoal da LSF, que se refere ao estabelecimento de relações humanas, à "linguagem como ação", que é "interativa e pessoal” (HALLIDAY; MATTHIESSEN, 2014,

\footnotetext{
${ }^{3}$ No original: "Representation corresponds to Halliday's 'ideational' function; Action is closest to his 'interpersonal' function, though it puts more emphasis on text as a way of (inter)acting in social events, and it can be seen as incorporating Relation (enacting social relations); Halliday does not differentiate a separate function to do with identification - most of what I include in Identification is in his 'interpersonal' function. I do not distinguish a separate 'textual' function, rather I incorporate it within Action." (FAIRCLOUGH, 2003, p. 27).

${ }^{4}$ No original: "[...] we can locate appraisal as an interpersonal system at the level of discourse semantics" (MARTIN; WHITE, 2005, p. 33).
} 
p. 30). Para White (2011, p. 14, tradução nossa) ${ }^{5}$, o SA fornece "técnicas para a análise sistemática de avaliação e de postura", preocupando-se com "a função social desses recursos [de avaliação e de postura], não apenas como o meio pelo qual falantes/escritores individuais expressam seus sentimentos e se posicionam, mas como o meio pelo qual eles se envolvem com posições de valor determinadas socialmente".

É importante destacar que o SA também dialoga com a metafunção ideacional, uma vez que há elementos verbais como os processos ${ }^{6}$, por exemplo, que marcam a avaliação como: angustiar, que é um processo mental emotivo que pode marcar uma avaliação de Afeto negativa. Conforme Scherer e Motta-Roth (2015, p. 268), "a metafunção ideacional, em seu sistema de Transitividade, realiza o conteúdo proposicional do texto, possibilitando, ao sujeito representar as experiências do mundo interior e exterior - é o campo do discurso". Nessa perspectiva, a oração é composta por processos, participantes e circunstâncias. Na figura 2, a seguir, apresentamos esses componentes segundo Fuzer e Cabral (2014).

\begin{tabular}{|c|c|c|c|}
\hline Componentes & Definição & $\begin{array}{l}\text { Categoria } \\
\text { gramatical } \\
\text { típica }\end{array}$ & Exemplo \\
\hline Processos & $\begin{array}{l}\text { São o elemento central da oração e representam as } \\
\text { experiências, as atividades que realizamos, os } \\
\text { aspectos do mundo, tanto o físico, quanto o social e } \\
\text { o mental. }\end{array}$ & $\begin{array}{l}\text { Grupos } \\
\text { verbais }\end{array}$ & $\begin{array}{l}\text { Júlia inventou uma } \\
\text { desculpa no trabalho }\end{array}$ \\
\hline Participantes & $\begin{array}{l}\text { São as entidades envolvidas - pessoas ou coisas, } \\
\text { seres animados ou inanimados --, as quais levam à } \\
\text { ocorrência do processo ou são afetadas por ele. } \\
\text { Recebem classificações específicas para cada tipo } \\
\text { de processo. }\end{array}$ & $\begin{array}{l}\text { Grupos } \\
\text { nominais }\end{array}$ & $\begin{array}{l}\text { Júlia inventou uma } \\
\text { desculpa no trabalho }\end{array}$ \\
\hline Circunstâncias & $\begin{array}{l}\text { Indicam, opcionalmente, o modo, o tempo, o lugar, } \\
\text { a causa, o âmbito em que o processo se desdobra. }\end{array}$ & $\begin{array}{c}\text { Grupos } \\
\text { adverbiais }\end{array}$ & $\begin{array}{l}\text { Júlia inventou uma } \\
\text { desculpa no trabalho }\end{array}$ \\
\hline
\end{tabular}

$$
\text { Figura } 2 \text { - Componentes da oração }
$$

Fonte: Baseada em Fuzer e Cabral (2014, p. 41), elaborada pelas autoras

Fuzer e Cabral (2014, p. 46) explanam que "orações que realizam diferentes tipos de processos têm contribuições distintas para a construção da experiência nos textos" e podem materializar avaliações. Desse modo, o SA relaciona-se às metafunções interpessoal e ideacional.

\footnotetext{
${ }^{5}$ No original: "It provides techniques for the systematic analysis of evaluation and stance $[\ldots]$ It is concerned with the social function of these resources, not simply as the means by which individual speakers/writers express their feelings and take stands, but as the means by which they engage with socially-determined value positions" (WHITE, 2011, p. 14).

${ }^{6}$ Os processos se dividem em: materiais, mentais, relacionais, existenciais, verbais e comportamentais (FUZER; CABRAL, 2014). A partir da classificação dos processos que as orações são classificadas e seus participantes identificados.
} 
O SA divide-se em três Subsistemas: Atitude, Engajamento e Gradação. Para nossa análise, trabalharemos com os Subsistemas de Atitude e Gradação. Decidimos esse recorte porque, após a leitura da reportagem selecionada para análise, percebemos que as marcas de avaliação ligadas a esses dois Subsistemas mostraram-se como as mais relevantes para discussão de identificações. Martin e White explicam que a

Atitude se preocupa com nossos sentimentos, incluindo reações emocionais, julgamentos de comportamento e apreciação de coisas. Engajamento lida com atitudes de terceirização e com o jogo de vozes em torno de opiniões no discurso. Gradação atende a fenômenos de classificação pelos quais os sentimentos são amplificados e categorias borradas. (MARTIN; WHITE, 2005, p. 35, tradução nossa) ${ }^{7}$.

Dentro do Subsistema da Atitude, encontramos três regiões semânticas: Afeto, Julgamento e Apreciação. O Afeto está relacionado aos recursos para a construção de reações emocionais. O Julgamento preocupa-se com recursos para avaliar o comportamento de acordo com diferentes princípios e normas. Já a Apreciação trata das questões de interpretação do valor das coisas, incluindo os fenômenos naturais e a semiose. Essas distinções podem ser observadas nos exemplos da figura 3, a seguir.

\begin{tabular}{|l|l|l|}
\hline Tipo de avaliação & \multicolumn{1}{|c|}{ Exemplo } & \multicolumn{1}{c|}{ Detalhamento } \\
\hline Afeto & {$[\ldots]$ a angustiava havia dois meses. } & $\begin{array}{l}\text { O processo mental angustiava evidencia um Afeto } \\
\text { negativo de infelicidade. A variável in/felicidade } \\
\text { diz respeito a emoções ligadas ao coração como, } \\
\text { por exemplo, amor, ódio, felicidade e tristeza. }\end{array}$ \\
\hline Julgamento & $\begin{array}{l}\text { Comprou clandestinamente } \\
\text { comprimidos abortivos. }\end{array}$ & $\begin{array}{l}\text { O atributo clandestinamente realiza um Julgamento } \\
\text { de sanção social propriedade. A sanção social está } \\
\text { ligada às questões legais e morais, no trecho do } \\
\text { exemplo isso diz respeito à ilegalidade de venda de } \\
\text { tais comprimidos e da prática de aborto. }\end{array}$ \\
\hline Apreciação & $\begin{array}{l}\text { O atendimento às vítimas de } \\
\text { violência sexual é de baixíssima } \\
\text { complexidade. }\end{array}$ & $\begin{array}{l}\text { O atributo baixíssima complexidade faz uma } \\
\text { Apreciação de composição complexidade negativa } \\
\text { do atendimento às vítimas. }\end{array}$ \\
\hline
\end{tabular}

Figura 3 - Exemplos de avaliações por região semântica no corpus

Fonte: elaborada pelas autoras

Os próprios autores, no entanto, questionam as divisões entre as regiões semânticas, uma vez que as categorias podem se efetivar de diversas formas por meio de atributos, circunstâncias, nomes e processos (WHITE, 2004). Além disso, as três categorias estão

\footnotetext{
${ }^{7}$ No original: "Attitude is concerned with our feelings, including emotional reactions, judgements of behavior and evaluation of things. Engagement deals with sourcing attitudes and the play of voices around opinions in dis course. Graduation attends to grading phenomena whereby feelings are amplified and categories blurred." (MARTIN; WHITE, 2005, p. 35).
} 
fundamentalmente interligadas, já que todas se relacionam à expressão de sentimentos, "a diferença é que a fundamentação desses sentimentos varia ao longo dos três modos" (WHITE, 2004, p. 182-183). Isto é, no Afeto, a ação da emoção é indicada diretamente; enquanto, no Julgamento e na Apreciação, esses sentimentos são, em algum grau, institucionalizados e representados como partes intrínsecas ao fenômeno avaliado. É importante lembrar que os valores afetivos estão subentendidos em todas as subcategorias da Atitude, já que, geralmente, compartilham o léxico. Para White,

há uma diferença retórica significativa em jogo na escolha entre uma avaliação ancorada nas reações emocionais de um sujeito humano específico e uma externalização desse sentimento representando-o como uma característica inerente da entidade avaliada em si. Em outras palavras, consideramos importante fazer uma distinção entre construir as emoções de um sujeito humano (Afeto) e atribuir a coisas o poder de gerar essas emoções (Apreciação). (WHITE, 2004, p. 192).

Martin e White (2005) exploraram também as avaliações implícitas. Para eles, é completamente possível que partes do texto invoquem avaliações " [...] mesmo na ausência de léxico atitudinal, que nos diga diretamente como sentir" (MARTIN; WHITE, 2005, p. 62, tradução nossa) ${ }^{8}$. White (2004) comenta a complicação teórica e analítica que a possibilidade de analisar questões implícitas levanta, mas defende que ignorar tais avaliações não é propício, uma vez que uma análise que considera apenas a avaliação inscrita "não somente seria incapaz de lidar com o papel da avaliação implícita em geral, como também não levaria em conta a interação, muitas vezes crucial em termos retóricos, entre avaliações diretas e indiretas." (WHITE, 2004, p. 181). Os autores propõem uma divisão quanto à natureza das avaliações implícitas, assim elas são provocadas ou evocadas. A diferença entre as que podem ser categorizadas como implícitas evocadas (que trazem à mente do leitor a valoração) e as provocadas se dá na medida em que, nas últimas, "o enunciado provoca no leitor uma inferência de um valor" (IKEDA, 2010, p. 173, grifo da autora). A realização implícita também pode ser revelada por elementos identificáveis do Sistema da Transitividade. Na figura 4, a seguir, trazemos um exemplo do corpus. Além disso, os autores propõem que todas avaliações podem ser classificadas quanto à polaridade, que pode ser positiva, negativa ou ambígua.

\footnotetext{
${ }^{8}$ No original: "[...] even in the absence of attitudinal lexis that tells us directly how to feel." (MARTIN; WHITE, 2005, p. 62).
} 


\begin{tabular}{|c|c|l|}
\hline $\begin{array}{c}\text { Tipo de avaliação } \\
\text { implícita }\end{array}$ & \multicolumn{1}{|c|}{ Exemplo } & \multicolumn{1}{c|}{ Detalhamento } \\
\hline Afeto de insegurança & $\begin{array}{l}\text { Júlia inventou uma desculpa } \\
\text { no trabalho [...] }\end{array}$ & $\begin{array}{l}\text { A escolha do processo mental inventar e do } \\
\text { participante uma desculpa constrói uma avaliação } \\
\text { negativa, uma vez que representa algo falso, tendo } \\
\text { em vista o tema da reportagem. }\end{array}$ \\
\hline
\end{tabular}

Figura 4 - Exemplo de avalição implícita

Fonte: elaborada pelas autoras

Sobre o Sistema da Gradação, Martin e White (2005, p. 37, tradução nossa) ${ }^{9}$ explicam que ele se "preocupa com a gradabilidade. Para Atitude, uma vez que os recursos são inerentemente graduáveis, a graduação tem a ver com o ajuste do grau de uma avaliação". Ou seja,

O fenômeno da gradação refere-se à utilização de recursos lexicogramaticais pelos falantes para expressar e ajustar o que Martin (1997), Martin e Rose (2003) e Martin e White (2005) descrevem como o grau, ou 'volume', da intensidade das avaliações de julgamento, afeto e apreciação disponíveis no Sistema de Atitude e o 'volume' da intensidade dos recursos de posicionamento intersubjetivo disponíveis no Sistema de Engajamento. (SOUZA, 2010, p. 191).

Os autores apontam que a gradabilidade é uma propriedade de todos os significados atitudinais, que é observável nos valores de Afeto, Julgamento e Apreciação pela maneira como "[...] eles constroem maiores ou menores graus de positividade ou negatividade" (MARTIN; WHITE, 2005, p. 135, tradução nossa) ${ }^{10}$. A Gradação é dividida em dois Subsistemas: Força e Foco. Souza (2010, p. 192), explica que o Subsistema de Força "oferece recursos para graduar qualidades (p. ex.: inteligente, bonito, feio, medroso) e processos (p. ex.: andar, correr, comer, pedir)"; enquanto o Foco proporciona recursos para "graduar categorias semânticas prototípicas que em princípio não são passíveis de serem graduadas (p. ex.: pai, professora, cadeira, livro)". Na figura 5, a seguir, apresentamos dois exemplos de Gradação retirados do corpus.

\begin{tabular}{|l|l|}
\hline \multicolumn{1}{|c|}{ Classificação } & \multicolumn{1}{c|}{ Exemplo } \\
\hline $\begin{array}{l}\text { Força intensificação por } \\
\text { repetição }\end{array}$ & $\begin{array}{l}\mathrm{O} \text { atendimento às vítimas de violência sexual é de baixíssima } \\
\text { complexidade. Qualquer serviço minimamente estruturado, mesmo que só } \\
\text { com uma enfermeira treinada, consegue fazer. }\end{array}$ \\
\hline Foco acentuação & $\begin{array}{l}\text { Dios conduziu 82 entrevistas com profissionais de saúde em cinco capitais } \\
\text { e identificou uma série de entraves. }\end{array}$ \\
\hline
\end{tabular}

Figura 5 - Exemplos de gradação

Fonte: elaborada pelas autoras

\footnotetext{
${ }^{9}$ No original: "[...] is concerned with gradability. For attitude, since the resources are inherently gradable, graduation has to do with adjusting the degree of an evaluation" (MARTIN; WHITE, 2005, p. 37).

${ }_{10}$ No original: "[...] they construe greater or lesser degrees of positivity or negativity." (MARTIN; WHITE, 2005, p. 135).
} 
Para Força, Martin e White (2005) apontam duas opções de categorização: a intensificação, relacionada à Gradação de processos, qualidades e indicadores de modalidade (se dividindo em: de grau para qualidades e vigor para processos); e a quantificação, que atua na Gradação de entidades, dividindo-se em de quantidade, de volume e de extensão, essa última pode ser classificada entre proximidade ou distribuição. Esses recursos são executados através de diversos recursos léxicogramaticais: fusão, isolamento e repetição. Quando falamos em Foco, estamos nos referindo a categorias que, tipicamente, não são colocadas em escala. Assim, a Gradação opera "[...] para reconstruir essas categorias de tal maneira que participem de grupos escaláveis" (MARTIN; WHITE, 2005, p. 137, tradução nossa) ${ }^{11}$. Dessa forma, sob o Foco, é possível acentuá-las ou atenuá-las. Na próxima seção, realizamos a análise de excertos selecionados da reportagem de Gabriela Sá Pessoa.

\section{A mulher e o aborto na Folha de São Paulo}

Sabemos que as práticas sociais significam formas de atividade social relativamente estáveis e que seus momentos são: o mundo material, as pessoas, a ação e interação, as relações sociais e o discurso, elementos esses que estabelecem entre si uma relação de internalização e de articulação (CHOULIARAKI; FAIRCLOUGH, 1999). Nessa perspectiva, compreendemos que a prática do aborto envolve as mulheres que abortam e várias outras pessoas, com suas crenças, valores, desejos, costumes e ideologias; as suas ações e interações; instituições; atividades materiais e o discurso/semiose. No texto do corpus, temos uma representação discursiva dessa prática social.

Como explicado anteriormente, a reportagem Mulheres têm que viajar a São Paulo por aborto legal, assinada por Gabriela Sá Pessoa e publicada na Folha de São Paulo online no dia 23 de fevereiro de 2019, foi a primeira do ano a trazer para o texto a voz das mulheres que abortaram. No jornalismo, a este tipo de fonte cabe a classificação ilustrativa (BELTRÃO, 1969), que é utilizada pela jornalista para exemplificar a história contada na matéria. As fontes ilustrativas são essenciais em matérias jornalísticas que tratem de assuntos de interesse da população (especialmente sobre saúde pública, como é o caso da prática social de aborto), já que permite aos leitores uma aproximação com o tema e mostra de forma mais perceptível a relevância dele.

\footnotetext{
${ }^{11}$ No original: "[...] to reconstrue these categories in such a way that they participate in scalable clines of prototypicality" (MARTIN; WHITE, 2005, p. 137).
} 
A reportagem de Gabriela Sá Pessoa se organiza ao redor das histórias contadas por duas mulheres: Júlia e Mariana (nomes fictícios), que tiveram de viajar até São Paulo em busca do direito ao abortamento legal. Ao contar a história dessas mulheres, a jornalista as entrelaça com fontes especialistas e oficiais (BELTRÃO, 1969), como o ginecologista André Luiz Malavasi, diretor do hospital Pérola Byington, buscado por Mariana e Júlia, e o Ministério da Saúde.

$\mathrm{Na}$ figura 6, a seguir, separamos alguns excertos da reportagem. A figura está organizada em três colunas: voz; ator social identificado e trecho. Em voz, indicamos a autoria do trecho exposto; em ator social identificado, apontamos quem foi avaliado no trecho; e, em trecho, está o recorte de fala como aparece na reportagem.

\begin{tabular}{|c|c|c|}
\hline Voz & $\begin{array}{l}\text { Ator social } \\
\text { identificado }\end{array}$ & Trecho \\
\hline \multirow[t]{3}{*}{$\begin{array}{l}\text { Gabriela Sá Pessoa: } \\
\text { autora da } \\
\text { reportagem }\end{array}$} & $\begin{array}{l}\text { Júlia (nome fictício): } \\
\text { mulher que buscou o } \\
\text { abortoamento legal } \\
\text { no Hospital Pérola } \\
\text { Byington }\end{array}$ & $\begin{array}{l}\text { EXCERTO 1: Depois de oito horas de viagem, Júlia (nome } \\
\text { fictício), 32, desembarcou sozinha em São Paulo numa manhã } \\
\text { de novembro, vinda do interior do Paraná, com pressa para } \\
\text { resolver um problema que, diz, a angustiava havia dois meses. } \\
\text { [... Sem avisar a ninguém, Júlia inventou uma desculpa no } \\
\text { trabalho e viajou sem nem saber direito onde dormiria. }\end{array}$ \\
\hline & $\begin{array}{l}\text { As mulheres que } \\
\text { buscam o aborto legal }\end{array}$ & $\begin{array}{l}\text { EXCERTO 2: O ginecologista André Luiz Malavasi, diretor } \\
\text { do Pérola, vê a peregrinação de mulheres como "a ponta do } \\
\text { iceberg" das falhas no atendimento a mulheres vítimas de } \\
\text { estupro. }\end{array}$ \\
\hline & $\begin{array}{l}\text { Mariana, outra vítima } \\
\text { de estupro que } \\
\text { buscou o abortamento } \\
\text { legal no Hospital } \\
\text { Pérola Byington }\end{array}$ & $\begin{array}{l}\text { EXCERTO 3: Mariana mora no interior do Paraná e também } \\
\text { teve de recorrer ao Pérola Byington [...]. Antes, tentou abortar } \\
\text { sozinha. Comprou clandestinamente comprimidos abortivos. } \\
\text { Nada funcionou. }\end{array}$ \\
\hline \multirow{3}{*}{$\begin{array}{l}\text { Mariana: mulher } \\
\text { que buscou o } \\
\text { abortamento legal } \\
\text { no Hospital Pérola } \\
\text { Byington }\end{array}$} & A própria Mariana & $\begin{array}{l}\text { EXCERTO 4: "Entrei numa crise de depressão, tentei me } \\
\text { matar", conta. }\end{array}$ \\
\hline & $\begin{array}{l}\text { As mulheres } \\
\text { brasileiras de forma } \\
\text { geral }\end{array}$ & $\begin{array}{l}\text { EXCERTO 5: "E essa visão de que a mulher ainda é colocada } \\
\text { como errada fez com que eu não recorresse a ninguém. } \\
\text { Ninguém quer divulgar [a lei], existe um sigilo muito forte." }\end{array}$ \\
\hline & \multirow[t]{2}{*}{ O aborto legal } & $\begin{array}{l}\text { EXCERTO 6: "Na minha cabeça sempre funcionou como um } \\
\text { boato", responde. }\end{array}$ \\
\hline $\begin{array}{l}\text { André Luiz } \\
\text { Malavasi: diretor do } \\
\text { hospital Pérola } \\
\text { Byington }\end{array}$ & & $\begin{array}{l}\text { EXCERTO 7: "O abortamento é o colapso da prevenção da } \\
\text { violência, da assistência à saúde. Mostra que falhamos em } \\
\text { todos os sentidos", ele diz. "O atendimento às vítimas de } \\
\text { violência sexual é de baixíssima complexidade. Qualquer } \\
\text { serviço minimamente estruturado, mesmo que só com uma } \\
\text { enfermeira treinada, consegue fazer." }\end{array}$ \\
\hline
\end{tabular}

Figura 6 - As mulheres na Folha de São Paulo

Fonte: elaborada pelas autoras

No excerto 1, Júlia é identificada por meio da circunstância de acompanhamento sozinha, que realiza uma avaliação negativa implícita. Essa Atitude negativa fica clara à 
medida que avançamos no texto. Ademais, essa circunstância se repete ao longo da narrativa com a outra personagem apresentada. Além disso, a sequência de escolhas lexicogramaticais que realizam Afetos negativos de infelicidade e insegurança, presentes em: problema; angustiava (processo mental emotivo); sem avisar a ninguém (circunstância de contingência); Júlia inventou uma desculpa (na oração mental cognitiva; Afeto de insegurança implícito, provocado pelo contexto); e sem nem saber direito onde dormiria (circunstância de contingência), contribuem para a solidificação da representação do aborto como um tema que deve ser escondido, pois é entendido socialmente como vergonhoso; e das mulheres enquanto personagens solitárias que não contam com ajuda quando o assunto é violência sexual e aborto.

A expressão peregrinação de mulheres, no excerto 2 , é uma escolha que identifica a viagem de mulheres brasileiras de todos os estados até o Hospital Pérola Byington em São Paulo, para serem atendidas pelo serviço de aborto legal no hospital, como uma viagem a um lugar que é considerado santo. O uso dessa expressão compõe uma avaliação das mulheres enquanto peregrinas que, na base da fé, buscam seus direitos. Nesse excerto, peregrinação de mulheres é identificada como uma das falhas (atributo) no atendimento às mulheres e meninas que buscam o serviço de abortamento legal, o atributo realiza uma Apreciação de composição de proporção negativa do atendimento e provoca uma Avaliação negativa implícita sobre a atuação governamental.

Além disso, o mesmo trecho identifica as mulheres como vítimas de estupro (atributo), que estão sempre sozinhas e isoladas socialmente, ideias reforçadas pelos excertos 1 e 3 . Os excertos 3 e 4, na figura 6, apresentam outra mulher atendida pelo hospital: Mariana, que, como Júlia, é identificada como sozinha (circunstância de acompanhamento), aqui na sua tentativa de autoaborto. Por meio da repetição da circunstância sozinha e dos trechos crise de depressão e tentei me matar, que realizam Afetos de infelicidade, a reportagem reforça a representação de solidão que envolve o abortamento e os efeitos disso no estado emocional das mulheres. Notamos que há um padrão na maneira como elas são identificadas a partir de fatores emocionais, como o foco nos sentimentos de angústia da Júlia e a depressão da Mariana. Essas identificações evidenciam problemas comuns em pessoas vítimas de estupro. Souza, Drezett, Meirelles e Ramos (2013, p. 102) explicam que "mulheres que sofrem violência sexual apresentam índices mais severos de transtornos e consequências psicológicas, como TEPT, depressão, ansiedade, transtornos alimentares, distúrbios sexuais e distúrbios do humor". 
No excerto 3, a circunstância de modo clandestinamente realiza Julgamento de sanção social, relacionado à ilegalidade da prática de aborto. Corrêa, Alves e Jannuzzi (2006, p. 115) apontam que, no Brasil, a criminalização "não visa aprisionar todas as pessoas que cometem esses 'crimes', mas sim criar e sustentar uma atmosfera 'moral' de condenação". Por esse motivo, a lei é aplicada "episodicamente, pois só assim as sociedades (e pessoas) 'se lembram' de que a norma existe" (CORRÊA; ALVES; JANNUZZI, 2006, p. 115). De forma geral, a execução da lei penal, nos casos de aborto, é feita sobre aquelas que já são fragilizadas socialmente por meio de outras formas de desigualdades, como as mulheres negras, pobres e de periferia (CORRÊA; ALVES; JANNUZZI, 2006). Estes autores observam um movimento da aplicação da lei com sentido moral, o que, no SA, seria associado à questão de Julgamento de estima social, se não tratássemos de um assunto tipificado no Código Penal Brasileiro.

No excerto 5, Mariana faz referência a uma identificação tradicionalmente construída para a mulher como errada, em: a mulher (portador) ainda (circunstância extensão) é colocada (processo relacional atributivo) como errada (atributo), realizando um Julgamento de estima social negativo. A oração é altamente intertextual com o discurso machista aqui internalizado e reproduzido por Mariana, e as suposições construídas socialmente sobre a culpa da mulher estuprada. Essa intertextualidade é estabelecida com textos como: "mas ela estava de saia curta”, "ela não deveria andar sozinha à noite”, "ela estava pedindo”, "ela estava provocando", "ela estava bêbada", que circulam socialmente quando algum crime de estupro é comentado.

Um exemplo desse tipo de representação foi evidenciado em um caso na Irlanda, em 2018, quando um estuprador foi inocentado após sua advogada apresentar a calcinha da vítima no julgamento para qualificá-la como uma mulher de má índole e ligar o fio-dental ao consentimento (SAFRONOVA, 2018). No Brasil, o caso da influencer Mariana Ferrer esteve em evidência na mídia brasileira pela defesa do indiciado apresentar fotos publicadas na rede social de Mariana buscando deslegitimá-la e pela decisão do juiz de inocentar o agressor, fundamentada na justificativa de que não havia uma intenção de estuprar (ALVES, 2020). Nesse caso, as provas do exame de corpo de delito, o material genético, as gravações de câmeras de segurança e a opinião pública favorável a Mariana, não foram suficientes para superar o poder hegemônico patriarcal e sexista.

No excerto 6, Mariana qualifica o direito ao aborto legal com o atributo boato, que reforça sua fala sobre a lei estar sob um sigilo muito forte (cf. figura 6, excerto 5). A identificação realizada por ela concorda com os dados coletados pelo Mapa do Aborto Legal 
(ARTIGO 19, 2018) sobre a dificuldade de encontrar e pouca clareza nas informações sobre o direito ao aborto legal nos sites oficiais do Ministério da Saúde. Destacamos, também, que a identificação do aborto legal enquanto boato é sintomática não só dos tabus da sociedade brasileira, como também das falhas da mídia em sua função de fiscalizadora das instituições e em seu princípio de responsabilidade social (PEREIRA, 2004), uma vez que o atributo utilizado por Mariana traz ao campo discursivo as barreiras criadas pelo próprio Estado no acesso a um direito garantido desde 1940.

Indo mais a fundo na questão, encontramos dados de 2014 presentes na pesquisa "Estupro no Brasil: uma radiografia segundo os dados da Saúde" (CERQUEIRA; COELHO, 2014), que estima em 527 mil o número de pessoas estuprada por ano no país, apenas 10\% (52.700) denunciam. Entre os notificados, 89\% das vítimas são do sexo feminino e delas $70 \%$ são crianças e adolescentes (CERQUEIRA; COELHO, 2014, p. 26). Além disso,

\begin{abstract}
crimes em que há penetração vaginal, em adolescentes entre 14 e 17 anos, redunda em uma grande taxa de gravidez, que ocorre em $15 \%$ dos casos. [...] Dentre as mulheres adultas que engravidaram, 19,3\% fizeram aborto legal. Esse indicador cai para 5\% quando a vítima possui entre 14 e 17 anos. (CERQUEIRA; COELHO, 2014, p. 27).
\end{abstract}

A partir desses dados, calculamos que são, aproximadamente, cinco mil gravidezes resultantes de estupros notificados entre crianças e adolescentes no Brasil por ano. E que apenas 250 delas, aproximadamente, conseguem realizar o abortamento legal.

Dentre as razões de tão poucas vítimas conseguirem o acesso ao abortamento legal estão o baixo número de hospitais que realizam o procedimento. Apesar da indicação do Ministério da Saúde (MS) de que todo hospital com setor de ginecologia e obstetrícia é equipado para a realização do procedimento e não deve negar atendimento a pacientes com a demanda de aborto dentro da lei (BRASIL, 2011), uma pesquisa da Artigo 19 mostra que a realidade não corresponde à determinação do MS. Embora conte com uma população de 211 milhões de pessoas, das quais pelo menos metade é do sexo feminino, sua dimensão continental e as altas taxas de violência contra mulher e estupro, o Brasil dispunha, em 2019, de apenas 76 hospitais que realizavam o procedimento de aborto legal em caso de estupro (ARTIGO 19, 2019). Por região, esses hospitais estavam distribuídos em: 5 hospitais no Norte, 20 no Nordeste, 6 no Centro Oeste, 35 no Sudeste e 10 no Sul. Em 2020, com a pandemia de Covid-19 e as mudanças sociais resultantes dela, o número caiu para 42 (ARTIGO 19, 2021).

No excerto 7, figura 6, destacamos o trecho da fala do médico André Luiz Malavasi sobre a prática do aborto em si: o abortamento (portador) é (processo relacional atributivo) $o$ 
colapso da prevenção da violência (atributo). A Atitude negativa é construída por meio de uma Apreciação de valoração social e está relacionada à representação da sociedade brasileira como insegura para mulheres e meninas. Em seguida, ele identifica, por meio de uma Apreciação de composição complexidade, o procedimento médico de abortamento como algo de baixíssima complexidade, simples de ser realizado por qualquer serviço minimamente estruturado e que apenas um profissional de enfermagem seria necessário. É interessante notar que as Gradações de Força intensificação de grau/qualidade, por meio de repetição de ideias, são utilizadas aqui para reforçar o quão fácil é o procedimento. Notamos, também, que há uma representação do serviço de enfermagem como algo mais básico do que o da medicina, além do estereótipo de gênero ao utilizar o feminino uma enfermeira.

\section{Considerações finais}

Ao fazermos uma análise das identificações do aborto e das mulheres que abortaram construídas em textos da Folha de São Paulo, compreendemos que há padrões de enquadramento do tema e dos atores sociais mulheres, que são observáveis a partir das escolhas lexicogramaticais utilizadas. Percebemos que as identificações prevalentes das mulheres que abortaram são relacionadas à solidão e à tristeza e realizadas por meio de avaliações de Afeto Infelicidade e Insegurança, evidenciadas nas escolhas: problema; angustiava; sem avisar a ninguém; inventou uma desculpa; sem nem saber direito onde dormiria; sozinha; vítima de estupro; crise de depressão; tentei me matar. Além disso, os Julgamentos negativos, tanto de estima social quanto de sanção social, reforçam o isolamento que os atores sociais envolvidos na prática de abortamento experienciam.

As identificações observadas no corpus deste artigo refletem a enormidade do problema social que é o abortamento legal. Nesse sentido, pouco se distingue da faceta ilegal da temática, quando consideramos os inúmeros entraves que as mulheres e meninas enfrentam na busca por um atendimento humanizado, como o caso de agosto de 2020, no qual o atendimento da menina capixaba de 10 anos, grávida decorrente de repetidos estupros, foi negado múltiplas vezes em seu estado natal (MAIA, 2020). Louzada (2020) percebe que o poder religioso, como mantenedor de costumes da vida privada, ressurgiu muito fortemente junto ao populismo político nos últimos dois anos. Esse debate

[...] é particularmente relevante para o tema do aborto, ao se considerar que uma das áreas mais recorrentes de embate entre secularismo e religião se refere ao "papel e impacto das religiões em opor, desacelerar, reverter ou circunscrever o alcance de 
plena igualdade para as mulheres" (Mancini, Rosenfeld, 2014, p. 19). (LOUZADA, 2020, p. 29).

De forma geral, a discussão sobre aborto no Brasil avançou pouquíssimo desde a legislação de 1940, Pinto (2003) classifica o tema como controverso. Isso porque, apesar de "ser uma prática bastante recorrente, a simples discussão sobre a possibilidade de sua legalização causa grande reação, principalmente da Igreja Católica" (PINTO, 2003, p. 83).

$\mathrm{Na}$ reportagem, vimos que o aborto legal é identificado em dois momentos, primeiro como boato, que retoma o contexto social brasileiro, no qual as informações sobre o direito ao aborto, sobre quem pode ter acesso a ele e sobre o que as mulheres precisam para acessá-lo são apagadas ou escondidas em sites governamentais. Segundo, por uma Apreciação de valoração social negativa, que apresenta a prática como uma falha do Estado na proteção de meninas e mulheres. Essas identificações evidenciam as falhas não só do Estado, mas também do jornalismo, uma vez que cabe à prática jornalística a função de fiscalização do Estado em nome dos cidadãos.

A prática jornalística, como defendemos na introdução, tem o poder de organizar os eventos sociais, de direcionar a forma como as práticas serão compreendidas por grupos políticos e pela sociedade civil, de dar destaque a certos temas e posições e de influenciar o modo como os leitores representam e identificam aspectos do mundo. Considerando isso, cabe destacar que a análise dos dados em questão mostra o quanto a linguagem em uso no texto materializa muito do que a mulher vivencia na nossa sociedade e como essa sociedade representa e avalia o aborto e a mulher que aborta. Há denúncia de graves problemas sociais, mas entendemos que, tendo em vista o princípio de responsabilidade social (PEREIRA, 2004) do jornalismo, é preciso que os jornalistas insistam na pauta até que esses problemas sejam resolvidos. Em outras situações fiscalizadas pelo jornalismo, como quando as vias públicas de uma cidade estão cheias de buracos, os jornalistas sabem da responsabilidade que têm de cobrar, do governo municipal, a correção do problema e insistem na pauta até a resolução. E isso deve ser feito em relação a todos os outros problemas.

Acreditamos que pesquisas sobre a prática social do aborto e sobre as representações e identificações dessa prática e dos atores sociais nela envolvidos em textos da esfera jornalística são atuais e relevantes, especialmente levando em consideração o momento de retrocessos nos direitos sexuais e reprodutivos que vivemos com o governo atual. Uma série de decisões tomadas pelo poder público em 2020 e 2021 mostrou que o Estado pretende, cada vez mais, dificultar o acesso ao abortamento legal, deixando as brasileiras ainda mais distantes das garantias de direitos fundamentais, como saúde e segurança. Nesse sentido, o 
jornalismo tem papel preponderante na luta contra essas decisões e a favor da garantia dos direitos humanos.

Entendemos que o estudo aqui representado tem suas limitações por tomar como material de análise apenas uma reportagem. Desse modo, outras investigações sobre o tema devem ser realizadas, como a pesquisa maior da qual este artigo é uma pequena parte. Sugerimos também que a prática social de aborto seja estudada de forma mais ampla e em estudos etnográficos que incluam as vozes das mulheres - as mais impactadas nesse tema com e por esse problema social.

\section{REFERÊNCIAS}

ALVES, Schirlei. Julgamento de influencer Mariana Ferrer termina com tese inédita de 'estupro culposo' e advogado humilhando jovem. The Intercept Brasil, Rio de Janeiro, 03 nov. 2020. Disponível em: https://theintercept.com/2020/11/03/influencer-mariana-ferrerestupro-culposo/. Acesso em 05 nov. 2020.

ARTIGO 19. Acesso à informação e aborto legal - mapeando desafios nos serviços de saúde. São Paulo: Artigo 19, 2019.

ARTIGO 19. Breve panorama sobre aborto legal e transparência no Brasil. São Paulo: Artigo 19, 2018.

ARTIGO 19. Mapa do Aborto Legal. Disponível em: https://mapaabortolegal.org/. Acesso em: 19 abr. 2021.

BRASIL. Decreto-lei no 2.848, de 7 de dezembro de 1940. Código Penal. Presidência da República, Rio de Janeiro, 1940. Disponível em:

http://www.planalto.gov.br/ccivil_03/decreto-lei/del2848compilado.htm. Acesso em 10 nov. 2020.

BRASIL. Ministério da Saúde. Secretaria de Atenção à Saúde. Departamento de Ações Programáticas Estratégicas. Atenção humanizada ao abortamento: norma técnica. 2 ed. Brasília: Ministério da Saúde, 2011, 60 p. Disponível em: https://catarinas.info/wpcontent/uploads/2018/04/atencao_humanizada_abortamento_norma_tecnica_2ed.pdf. Acesso em: 30 set. 2020.

BRASIL. Supremo Tribunal Federal. Arguição de Descumprimento de Preceito Fundamental. Anencefalia. Arguição de Descumprimento de Preceito Fundamental n. 54 ajuizada pela Confederação Nacional dos Trabalhadores da Saúde. Brasília, 433p. Disponível em: http://redir.stf.jus.br/paginadorpub/paginador.jsp?docTP=TP\&docID=3707334. Acesso em: 12 nov. 2020. 
CERQUEIRA, Daniel; COELHO, Danilo de S. C. Estupro no Brasil: uma radiografia segundo os dados da Saúde (versão preliminar). Brasília: Instituto de Pesquisa Econômica Aplicada. 2014. Disponível em: http://repositorio.ipea.gov.br/bitstream/11058/5780/1/NT_n11_Estupro-Brasilradiografia_Diest_2014-mar.pdf. Acesso em: 01 out. 2020.

CHOULIARAKI, Lilie; FAIRCLOUGH, Norman. Discourse in Late Modernity - Rethinking Critical Discourse Analysis. Edinburgh: Edinburgh University Press, 1999.

CORRÊA, Sônia; ALVES, José Eustáquio Diniz; JANNUZZI, Paulo de Martino. Direitos e saúde sexual e reprodutiva: marco teórico-conceitual e sistema de indicadores. In:

CAVENAGHI, S. (org.). Indicadores municipais de saúde sexual e reprodutiva. Rio de Janeiro: ABEP, Brasília: UNFPA, 2006. 282p. Disponível em:

http://www.abep.org.br/publicacoes/index.php/livros/issue/view/16/showToc. Acesso em: 15 abr. 2020.

FAIRCLOUGH, Norman. Critical Discourse Analysis: The Critical Study of Language. 2 ed. London: Routledge, 2010.

FAIRCLOUGH, Norman. Discurso e Mudança Social. Coordenação de Tradução de Izabel Magalhães. Brasília: Editora Universidade de Brasília, 2001.

FUZER, Cristiane; CABRAL, Sara R. S. Introdução à gramática sistêmico-funcional em língua portuguesa. Campinas: Mercado de Letras, 2014.

HALLIDAY, Michael K. A.; MATTHIESSEN, Christian M. I. M. An Introduction to Functional Grammar. 4th. ed. London: Arnold, 2014.

IKEDA, Sumiko N. O Julgamento na argumentação de um editorial. In: VIAN JR., O; SOUZA, A. A. de; ALMEIDA, F. S. D. P. A linguagem da avaliação em língua portuguesa: Estudos sistêmico-funcionais com base no Sistema da Avaliatividade. São Carlos: Pedro e João Editores, 2010. p. 167-188.

LOUZADA, Gabriela Rondon Rossi. Constitucionalismo agonístico: a questão do aborto no Brasil. 2020. 127 f. Tese (Doutorado em Direito) - Curso de Programa de Pós-Graduação em Direito, Universidade de Brasília, Brasília, 2020. Disponível em:

https://repositorio.unb.br/handle/10482/38629\#: :text=Constitucionalismo\%20agon\%C3\%A Dstico\%20\%3A\%20a\%20quest\%C3\%A30\%20do\%20aborto\%20no\%20Brasil.\&text=O\%20f oco\%20na\%20quest\%C3\%A3o\%20do,do\%20pol\%C3\%ADtico\%20para\%20o\%20tema. Acesso em: 28 set. 2020.

MAGALHÃES, Izabel; MARTINS, André R.; RESENDE, Viviane M. Análise de Discurso Crítica: um método de pesquisa qualitativa. Brasília: Editora da Universidade de Brasília, 2017.

MAIA, Dhiego. Menina que engravidou após estupro teve que sair do ES para fazer aborto legal. Folha de São Paulo, São Paulo, 16 ago. 2020. Cotidiano. Disponível em: https://www1.folha.uol.com.br/cotidiano/2020/08/menina-que-engravidou-apos-estupro-teveque-sair-do-es-para-fazer-aborto-legal.shtml. Acesso em: 18 ago. 2020. 
MARTIN, J. R.; WHITE, Peter R. R. The language of evaluation - appraisal in English. Londres: Palgrave/Macmillan, 2005.

PEREIRA, Fábio Henrique. Da responsabilidade social ao jornalismo de mercado: o jornalismo como profissão. Lisboa: Biblioteca On-line de Ciências da Comunicação, 2004. Disponível em: http://www.bocc.ubi.pt/pag/pereira-fabioresponsabilidade-jornalista.pdf. Acesso em: 23 out. 2020.

PESSOA, Gabriela Sá. Mulheres têm que viajar a São Paulo por aborto legal. Folha de São Paulo, São Paulo, 23 fev. 2019. Cotidiano. Disponível em:

https://www1.folha.uol.com.br/cotidiano/2019/02/mulheres-tem-que-viajar-a-sao-paulo-poraborto-legal.shtml. Acesso em: 10 mar. 2020.

PINTO, Céli Regina Jardim. Uma história do feminismo no Brasil. São Paulo: Editora Fundação Perseu Abramo, 2003.

ROHDEN, Fabíola. A arte de enganar a natureza: contracepção, aborto e infanticídio no início do século XX. Rio de Janeiro: Editora Fiocruz, 2003.

SAFRONOVA, Valeriya. Lawyer in Rape Trial Links Thong With Consent, and Ireland Erupts. The New York Times, New York, 15 nov. 2018. Europe. Disponível em: https://www.nytimes.com/2018/11/15/world/europe/ireland-underwear-rape-caseprotest.html\#: :text=A\%20criminal\%20trial\%20in\%20Ireland,across\%20the \%20country\%20 and $\% 20$ beyond.\&text=Hundreds $\% 20$ of $\% 20$ women $\% 20$ and $\% 20$ men, across $\% 20$ the $\% 20$ countr y\%20on\%20Wednesday. Acesso em: 31 out. 2020.

SCHERER, Anelise Scotti; MOTTA-ROTH, Désirée. Engajamento e redução do espaço dialógico no gênero notícia de popularização científica. Letras, Santa Maria, v. 25, n. 50, p. 261-302, jan./jun. 2015. Disponível em: https://periodicos.ufsm.br/letras/article/view/20213/pdf. Acesso em: 22 out. 2020.

SILVEIRA, Denise T.; CÓRDOVA, Fernanda P. A pesquisa científica. In: GERHARDT, Tatiana E.; SILVEIRA, Denise T (org.). Métodos de pesquisa. Porto Alegre: Editora da UFRGS, 2009. p. 31-41.

SOUZA, Anderson A. de. Gradação: força e foco. In: VIAN JR., O; SOUZA, A. A. de; ALMEIDA, F. S. D. P. A linguagem da avaliação em língua portuguesa: Estudos sistêmicofuncionais com base no Sistema da Avaliatividade. São Carlos: Pedro e João Editores, 2010. p. 191-204.

SOUZA, Flavia B. C.; DREZETT, Jefferson; MEIRELLES, Alcina de C.; RAMOS, Denise G. Aspectos psicológicos de mulheres que sofrem violência sexual. Elsevier, São Paulo, v. 27, n. 3, p. 98-103, set./dez. 2013. Disponível em:

https://www.sciencedirect.com/science/article/pii/S141320871300006X\#: :text=Resumo,dist \%C3\%BArbios\%20sexuais\%20e\%20do\%20humor. Acesso em: 20 mar. 2021.

VIAN JR., Orlando; SOUZA, Anderson A. de; ALMEIDA, Fabíola S. D. P. A linguagem da avaliação em língua portuguesa: Estudos sistêmico-funcionais com base no Sistema da Avaliatividade. São Carlos: Pedro e João Editores, 2010. 
WHITE, Peter R. R. Appraisal. In: ZIENKOWSKI, J.; ÖSTMAN, J.; VERSCHUEREN, J. Discursive pragmatic. v. 8. Amsterdam: John Benjamins B.V., 2011. p. 14-36.

WHITE, Peter R. R. Valoração: a linguagem da avaliação e da perspectiva. Linguagem em (Dis)curso - LemD, Tubarão, v. 4, n. esp., p. 178-205, 2004.

Artigo submetido em: 27 abr. 2021

Aceito para publicação em: 04 jun. 2021

DOI: http://dx.doi.org/10.22456/2238-8915.113446 